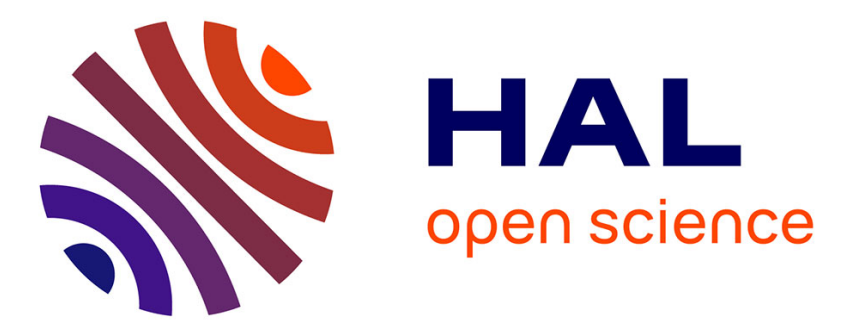

\title{
Oxygen uptake efficiency slope: a reliable surrogate parameter for exercise capacity in healthy and cardiac children?
}

Gavotto Arthur, d'Arcy Vandenberghe, Hamouda Abassi, Helena Huguet, Valérie Macioce, Marie-Christine Picot, Sophie Guillaumont, Stefan Matecki, Pascal Amedro

\section{To cite this version:}

Gavotto Arthur, d'Arcy Vandenberghe, Hamouda Abassi, Helena Huguet, Valérie Macioce, et al.. Oxygen uptake efficiency slope: a reliable surrogate parameter for exercise capacity in healthy and cardiac children?. Archives of Disease in Childhood, In press, pp.archdischild-2019-317724. 10.1136/archdischild-2019-317724 . hal-02910224v2

\section{HAL Id: hal-02910224 \\ https://hal.science/hal-02910224v2}

Submitted on 8 Sep 2020

HAL is a multi-disciplinary open access archive for the deposit and dissemination of scientific research documents, whether they are published or not. The documents may come from teaching and research institutions in France or abroad, or from public or private research centers.
L'archive ouverte pluridisciplinaire HAL, est destinée au dépôt et à la diffusion de documents scientifiques de niveau recherche, publiés ou non, émanant des établissements d'enseignement et de recherche français ou étrangers, des laboratoires publics ou privés. 


\title{
Oxygen uptake efficiency slope: a reliable surrogate parameter for exercise capacity in healthy and cardiac children?
}

\author{
Arthur Gavotto ${ }^{1,2}$ D'arcy Vandenberghe, ${ }^{1}$ Hamouda Abassi, ${ }^{1}$ Helena Huguet, ${ }^{3,4}$ \\ Valerie Macioce, ${ }^{3}$ Marie-Christine Picot, ${ }^{3,4}$ Sophie Guillaumont, ${ }^{1,5}$ Stefan Matecki, ${ }^{1,6}$ \\ Pascal Amedro
}

${ }^{1}$ Pediatric and Congenital Cardiology Department, M3C Regional Reference CHD Centre, Clinical Investigation Centre, Montpellier University Hospital, Montpellier, France

${ }^{2}$ PhyMedExp, CNRS, INSERM, University of Montpellier, Montpellier, France

${ }^{3}$ Epidemiology and Clinical Research Department,

Montpellier University Hospital, Montpellier, France

${ }^{4}$ Epidemiology and Biostatistics, Clinical Investigation Centre,

INSERM, University of Montpellier, France, Montpellier, France

${ }^{5}$ Pediatric and Congenital Cardiology and Rehabilitation Unit, St-Pierre Institute, PalavasLes-Flots, France

${ }^{6}$ Pediatric Functional Exploration Laboratory, Physiology Department, Montpellier University Hospital, Montpellier, France

\section{Correspondence to}

Dr Gavotto Arthur, Hopital Arnaud de Villeneuve, Montpellier 34295, France; a-gavotto@chu-montpellier.fr

\begin{abstract}
Objectives Cardiopulmonary exercise test (CPET) provides accurate evaluation of physical capacity and disease severity in children with congenital heart disease (CHD). However, full participation to obtain optimal measure of $\mathrm{VO}_{2 \max }$ may be difficult. As an alternative, the oxygen uptake efficiency slope (OUES) is a reproducible and reliable parameter measured during CPET, which does not require a maximal exercise to be interpretable. This study aimed to evaluate the OUES of a large cohort of children with CHD, in comparison with healthy controls. We also intended to identify, in this specific population, the clinical and CPET variables associated with the OUES.
\end{abstract}

Methods This cross-sectional study was carried out between November 2010 and September 2015 in two tertiary care paediatric and congenital cardiology centres. Results 709 children were included (407 CHD and 302 healthy controls). The association of clinical characteristics with weight-normalised OUES (OUES ${ }_{\mathrm{kg}}$ ) was studied using a multivariable analysis. The mean $\mathrm{OUES}_{\mathrm{kg}}$ was significantly lower in CHD than in healthy controls (38.6 \pm 8.5 and $43.9 \pm 8.5 ; p<0.001$, respectively), especially in the most severe CHD. The OUES correlated $^{2}$ with $V_{2 \max }(r=0.85, p<0.001)$, with cut-off values for normal exercise capacity of 38.4 in boys and 31.0 in girls. The decrease of OUES $S_{\mathrm{kq}}$ was associated with increased age, increased Body Mass Index, number of cardiac catheter or surgical procedures, female gender and decreased forced vital capacity (Z-score).

Conclusion The OUES is significantly impaired in children with $\mathrm{CHD}$ and strongly correlates with $\mathrm{VO}_{\mathrm{max}}$ The OUES has the same clinical determinants as $\mathrm{VO}_{2 \max }$ and therefore may be of interest in submaximal exercise. Trial registration number NCT01202916.

\section{INTRODUCTION}

Cardiopulmonary exercise test (CPET) has become a key examination to assess physical capacity and disease severity in adult cardiology, ${ }^{1}$ as well as, more recently, in paediatric cardiology. ${ }^{2}$ Indeed, CPET provides an evaluation of the maximal oxygen uptake $\left(\mathrm{VCO}_{2 \max }\right)$, which correlates with both quality of life and prognosis. ${ }^{3}$

In clinical practice, a maximal CPET with optimal measure of $\mathrm{VO}_{2 \max }$ may be difficult to obtain in patients with congenital heart disease (CHD), especially in children. When the $\mathrm{VO}_{2 \max }$ does not reach

\section{What is already known on this topic?}

- Full participation to obtain optimal measure of $\mathrm{VO}_{2 \max }$ may be difficult.

- The oxygen uptake efficiency slope (OUES) does not require a maximal exercise to be interpretable.

\section{What this study adds?}

- The OUES is significantly impaired in children with congenital heart disease.

- The OUES strongly correlates with $\mathrm{VO}_{2 \max }$.

- The OUES has the same clinical determinants as $\mathrm{VO}_{2 \max }$

criteria for maximal effort, the peak VO2 is usually informed in paediatrics. ${ }^{45}$ Indeed, the quality of CPET measures can be strongly influenced by the motivation of patients, the type of exercise protocol and the laboratory technician's experience. ${ }^{6}$ As a maximal CPET does not reflect daily life physical activities, parameters evaluated during submaximal exercise have been considered as more clinically relevant. ${ }^{7}$ Indeed, based on submaximal CPET parameters such as the ventilatory anaerobic threshold (VAT), children with CHD are not limited in their submaximal exercise capacity. ${ }^{8}$ Similarly, in patients with severe cardiac conditions for which $\mathrm{VO}_{2 \max }$ measures are difficult to obtain, the ventilatory efficiency (VE/VCO2 slope) stands as a reliable submaximal parameter strongly correlated to prognosis. ${ }^{9}$

The oxygen uptake efficiency slope (OUES), which also does not require maximal exercise to be measured, has been previously used to evaluate exercise tolerance in healthy children and adults with chronic heart failure. ${ }^{10} 11$

The OUES is derived from the logarithmic relation between oxygen uptake and minute ventilation during incremental exercise, reflecting oxygen transport response to muscular oxygen consumption's increase. The OUES has been considered less dependent on the incremental protocol used for exercise testing than $\mathrm{VO}_{2 \max }$ and $\mathrm{VAT},{ }^{10}$ with reproducible and reliable results, it was interpretable in non-maximal exercise. ${ }^{12}$ A cut-off value of 


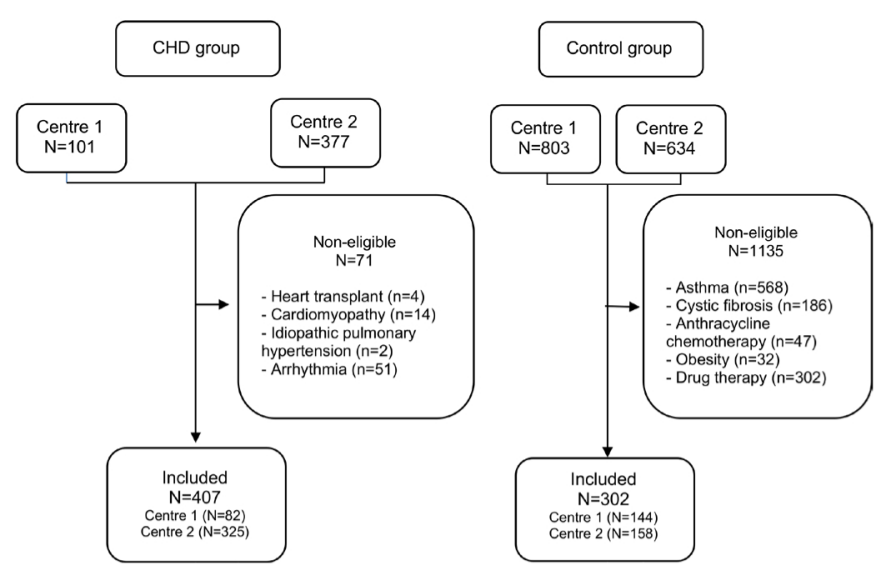

Figure 1 Flow chart. CHD, congenital heart disease.

weight-normalised OUES $\left(\right.$ OUES $_{\mathrm{kg}}$ ) $>34.6$ has been suggested by Hossri et al to identify children with normal functional capacity. ${ }^{13}$ In congenital cardiology, the OUES might discriminate children with CHD versus healthy children, ${ }^{14}$ and would even be superior to $\mathrm{VO}_{2 \max }$ in terms of cardiac morbidity prediction in patients with a Fontan circulation, ${ }^{15}$ as well as in heart failure. ${ }^{16}$ Recently, the OUES has been used as a predictor of cardiac hospitalisation for patients with repaired tetralogy of Fallot ${ }^{17}$ and pulmonary hypertension. ${ }^{18} 19$

Nevertheless, as opposed to $\mathrm{VO}_{2 \max }$, VAT and VE/VO2 slope, the OUES remains scarcely used in routine follow-up of cardiac patients, few CPET equipment manufacturers have incorporated OUES calculation in their software and no data from a large controlled cohort have established the interest of OUES in paediatric cardiology.

This study aimed to evaluate the OUES of a large cohort of children with CHD, and to compare the results with age-matched and gender-matched healthy controls. We also intended to identify, in this specific population, the clinical and CPET variables associated with the OUES.

Table 1 Main demographic and CPET data: comparison between CHD and control group

\begin{tabular}{lllc}
\hline & CHD & Control & P value \\
\hline $\mathrm{N}$ & 407 & 302 & - \\
\hline Age (years) & $12.2 \pm 3.4$ & $11.1 \pm 2.6$ & $<0.001$ \\
\hline Height (cm) & $150.9 \pm 17.6$ & $150.0 \pm 16.0$ & 0.40 \\
\hline Weight (kg) & $44.3 \pm 15.9$ & $42.2 \pm 13.3$ & 0.19 \\
\hline Sex ratio (male/female) & 1.3 & 1.3 & 0.80 \\
\hline $\mathrm{VO}_{2 \max }$ (mL/kg/min) & $37.7 \pm 6.9$ & $42.6 \pm 6.9$ & $<0.001$ \\
$\mathrm{VO}_{2 \max }$ predicts (\%) & $93.6 \pm 17.7$ & $106 \pm 17.7$ & $<0.001$ \\
$\mathrm{VO}_{2 \text { max }}$ predicts $<80 \%(\mathrm{n}, \%)$ & $104(25.6)$ & $19(6.3)$ & $<0.001$ \\
$\mathrm{VO}_{2 \max }$ predicts $\geq 80 \%(\mathrm{n}, \%)$ & $303(74.4)$ & $283(93.7)$ & \\
\hline Peak heart rate (beats per min) & $175.3 \pm 15.8$ & $187.6 \pm 15.9$ & $<0.001$ \\
\hline Percentage of predicted peak heart rate (\%) & $84.2 \pm 7.6$ & $90.1 \pm 7.6$ & $<0.001$ \\
\hline $\mathrm{RER}$ & $1.13 \pm 0.1$ & $1.13 \pm 0.1$ & 0.47 \\
\hline Maximum load (W) & $89.9 \pm 44.3$ & $121.8 \pm 44.2$ & $<0.001$ \\
\hline FEV1 (Z-score) & $-0.47 \pm 1.28$ & $0.40 \pm 1.09$ & $<0.001$ \\
\hline FVC (Z-score) & $-0.43 \pm 1.43$ & $0.41 \pm 1.26$ & $<0.001$ \\
\hline FEV1/FVC (Z-score) & $0.05 \pm 1.34$ & $0.04 \pm 1.18$ & 0.66 \\
\hline
\end{tabular}

Values are mean \pm SD.

$\mathrm{CHD}$, congenital heart disease; CPET, cardiopulmonary exercise test; \% FEV1, forced expiratory volume in $1 \mathrm{~s} ; \%$ FEV1/FVC, Tiffeneau index; \% FVC, forced vital capacity; RER, respiratory exchange ratio.

\section{METHODS}

\section{Study design}

This cross-sectional study was carried out between November 2010 and September 2015 in two tertiary care paediatric and congenital cardiology reference centres (centre 1: M3C Regional Pediatric and Congenital Cardiology Centre, Montpellier University Hospital, France; centre 2: Pediatric Cardiology and Rehabilitation Centre, Institut-Saint-Pierre, Palavas-Les-Flots, France).

\section{Patient population}

All children aged 5-18 years undergoing CPET in one of the two centres were assessed for eligibility, and eligible children were recruited after a regular paediatric cardiology outpatient visit. Two groups were identified: children with CHD and control children.

In the CHD group, the anatomic and clinical classification of CHD was used to define the type of malformation. ${ }^{20}$ The control group consisted of children referred for a non-severe functional symptom linked to exercise (murmur, palpitation or dyspnoea) or for a medical sports certificate. These children were classified in the control group only after a completely normal check-up, including physical examination, ECG, echocardiography and spirometry. Children with any chronic disease, medical condition (cardiac, neurological, respiratory, muscular or renal) or medical treatment and those requiring any further specialised medical consultation were not eligible.

\section{CPET procedures}

CPET procedures in both centres were harmonised before the study started. Both CPET laboratories used the same technical devices: paediatric face masks (Hans Rudolph, Shawnee, Kansas, USA), a calibrated gas analyser (Oxycon Pro, Jaeger, Erich Jaeger, Hoechberg, Germany), breath-to-breath measurement software (Windows V.98, Jaeger), 12-lead ECG equipment (CardioSoft, GE Healthcare, Little Chalfont, UK), a pulse oximeter (Nellcor, Medtronic, Fridley, Minnesota, USA) and a manual sphygmomanometer with adapted paediatric cuffs. Spirometry using a common gas device (Oxycon Pro, Jaeger, Erich Jaeger) was systematically performed before the exercise test with a flow volume curve and measurement of forced expiratory volume in $1 \mathrm{~s}$ (FEV1), forced vital capacity (FVC) and the FEV1/FVC ratio (FEV1\%), with normalisation to theoretical values. ${ }^{21}$

Both centres used the same CPET paediatric cycle ergometer protocol adapted to children with CHD to obtain a homogeneous incremental overall duration between 8 and 12 min: a $1 \mathrm{~min}$ rest; a 3 min warm-up (10-20 W) in increments of 10 , 15 or $20 \mathrm{~W}$ each minute; a pedalling rate of $60-80$ revolutions per minute; a $3 \mathrm{~min}$ active recovery $(20 \mathrm{~W})$ and a 2 min rest. ${ }^{22}$

The same investigator coordinator manually calculated the $\mathrm{VO}_{2 \max }$ and the OUES. The CPET was considered as maximal when three out of the four following criteria were reached: respiratory exchange ratio $(\mathrm{RER}=\mathrm{VCO} 2 / \mathrm{VO} 2) \geq 1.1$, maximum heart rate $>85 \%$ of maximal age-predicted heart rate, limit of the child's tolerance despite verbal encouragement, plateau of $\mathrm{VO} 2\left(\mathrm{VO}_{2 \max }\right)$ despite the increasing exercise intensity. When the $\mathrm{VO}_{2 \max }$ did not reach a plateau, the peak VO2 was informed, as usual in paediatrics. ${ }^{4}$ The same investigator coordinator manually calculated the $\mathrm{VO}_{2 \max }$ and the OUES. $\mathrm{VO}_{2 \max }$ values were normalised in a percentage of the predicted $\mathrm{VO}_{2 \max }$ using normal values from Cooper et al. ${ }^{23}$ The OUES is the slope of a regression line of oxygen uptake 


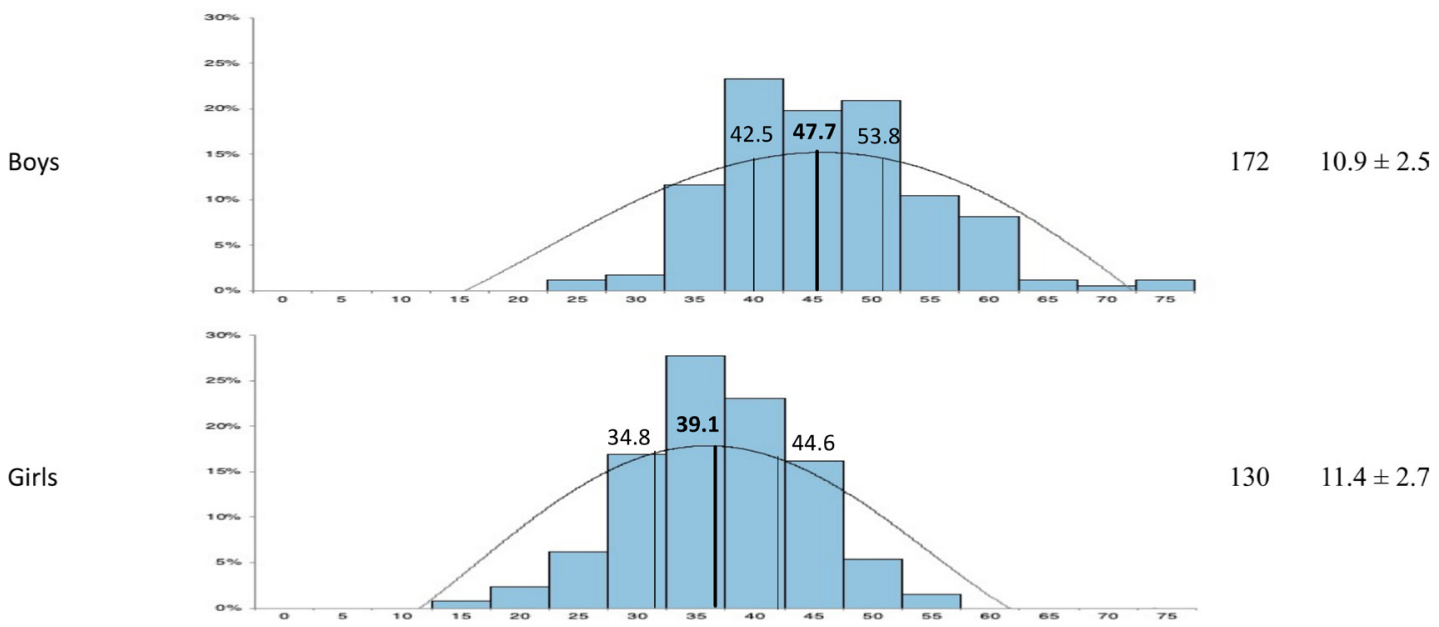

Figure 2 Weight-normalised oxygen uptake efficiency slope $\left(\mathrm{OUES}_{\mathrm{kg}}\right)$ in healthy boys and girls. The numbers above the density lines indicate $\mathrm{OUES}_{\mathrm{kg}}$ values for the 25th, 50th (bold) and 75th percentiles. Histograms represent the distribution of the OUES ${ }_{\mathrm{kg}}$ values for healthy boys and girls from the control group.

$\left(\mathrm{VO}_{2}\right)$ on logarithmically converted minute ventilation (VE) measured during incremental exercise: $\mathrm{VO}_{2}=\operatorname{alog}_{10} \mathrm{VE}+\mathrm{b} .{ }^{24}$ Here, ' $a$ ' is the OUES. The unit of $\mathrm{VO} 2$ is $\mathrm{mL} / \mathrm{min}$ and the unit of $\mathrm{VE}$ is $\mathrm{L} / \mathrm{min}$, therefore the OUES is a coefficient with no unit, which is usually divided by 1000 ( $\mathrm{mL}$ to L conversion).
The OUES was measured from the beginning of the exercise test to its maximal point and calculated from breath-by-breath data. As many parameters in paediatrics, the OUES is considerably influenced by anthropometric variables, therefore the weight-normalised value $\left(\mathrm{eg}\right.$, OUES $_{\mathrm{kg}}$ ) was informed. ${ }^{12526}$

Table 2 OUES in CHD and control group

\begin{tabular}{|c|c|c|c|c|c|c|c|c|}
\hline & & \multirow[b]{2}{*}{$\mathrm{N}_{\mathrm{CHD}} / \mathrm{N}_{\text {control }}$} & \multicolumn{3}{|l|}{ OUES $_{\mathrm{kg}}$} & \multicolumn{3}{|l|}{ OUES } \\
\hline & & & CHD & Control & $P$ value & CHD & Control & $P$ value \\
\hline \multicolumn{2}{|c|}{ Total } & $407 / 302$ & $38.6 \pm 8.5$ & $43.9 \pm 8.5$ & $<0.001^{*}$ & $1583 \pm 464$ & $1911 \pm 465$ & $<0.001^{*}$ \\
\hline \multicolumn{9}{|c|}{ Gender } \\
\hline \multicolumn{2}{|c|}{ Male } & $228 / 172$ & $41.1 \pm 9.1$ & $48.7 \pm 8.8$ & $<0.001$ & $1830 \pm 666$ & $2005 \pm 705$ & 0.01 \\
\hline \multicolumn{2}{|c|}{ Female } & $179 / 130$ & $35.8 \pm 8.7$ & $39.5 \pm 7.3$ & $<0.001$ & $1452 \pm 460$ & $1669 \pm 494$ & $<0.001$ \\
\hline \multicolumn{2}{|c|}{ ACC-CHD group } & $\mathrm{N}_{\mathrm{CHD}} / \mathrm{N}_{\text {control }}$ & CHD & Control & $P$ valuet & CHD & Control & $P$ valuet \\
\hline 1 & Heterotaxy & $3 / 36$ & $48.5 \pm 8.1$ & $46.0 \pm 10.8$ & 0.61 & $1559 \pm 736$ & $1647 \pm 2286$ & 0.69 \\
\hline 2 & Anomalies of the venous return & $12 / 130$ & $40.6 \pm 9.4$ & $44.8 \pm 18.2$ & 0.12 & $1665 \pm 685$ & $1750 \pm 1819$ & 0.51 \\
\hline 3 & $\begin{array}{l}\text { Anomalies of the atria and interatrial } \\
\text { communications }\end{array}$ & $24 / 157$ & $37.5 \pm 8.6$ & $42.2 \pm 13.1$ & 0.01 & $1670 \pm 624$ & $1935 \pm 1294$ & $<0.01$ \\
\hline 4 & $\begin{array}{l}\text { Anomalies of the atrioventricular } \\
\text { junctions and valves }\end{array}$ & $24 / 155$ & $37.0 \pm 9.9$ & $43.4 \pm 14.5$ & $<0.01$ & $1505 \pm 762$ & $1895 \pm 1658$ & $<0.001$ \\
\hline 5 & $\begin{array}{l}\text { Complex anomalies of atrioventricular } \\
\text { connections }\end{array}$ & $4 / 43$ & $33.2 \pm 7.7$ & $42.2 \pm 15.3$ & 0.02 & $1544 \pm 824$ & $2241 \pm 2452$ & $<0.01$ \\
\hline 6 & Functionally univentricular heart & $22 / 191$ & $34.2 \pm 9.8$ & $45.0 \pm 18.4$ & $<0.001$ & $1397 \pm 736$ & $2093 \pm 1873$ & $<0.001$ \\
\hline 7 & Ventricular septal defects & $41 / 269$ & $38.9 \pm 9.5$ & $44.8 \pm 15.0$ & $<0.001$ & $1751 \pm 682$ & $2057 \pm 1467$ & $<0.001$ \\
\hline 8.1 & Transposition of the great arteries & $55 / 260$ & $39.9 \pm 9.3$ & $46.0 \pm 12.9$ & $<0.001$ & $1865 \pm 784$ & $2087 \pm 1551$ & $<0.001$ \\
\hline 8.2 & $\begin{array}{l}\text { Tetralogy of Fallot; truncus arteriosus; } \\
\text { pulmonary atresia; double outlet right } \\
\text { ventricle }\end{array}$ & $71 / 289$ & $36.5 \pm 9.2$ & $44.0 \pm 13.0$ & $<0.001$ & $1451 \pm 671$ & $1929 \pm 1206$ & $<0.001$ \\
\hline 8.5 & Aortic valve stenosis; Shone syndrome & $44 / 267$ & $37.2 \pm 9.6$ & $43.9 \pm 15.1$ & $<0.001$ & $1686 \pm 706$ & $1998 \pm 1504$ & $<0.001$ \\
\hline 8.6 & Pulmonary valve stenosis & $44 / 281$ & $41.9 \pm 9.6$ & $43.9 \pm 15.4$ & 0.15 & $1721 \pm 656$ & $1885 \pm 1373$ & 0.02 \\
\hline 9 & $\begin{array}{l}\text { Anomalies of the extrapericardial } \\
\text { arterial trunks }\end{array}$ & $59 / 289$ & $41.0 \pm 9.5$ & $45.0 \pm 15.5$ & $<0.001$ & $1782 \pm 750$ & $2111 \pm 1514$ & 0.001 \\
\hline 10 & $\begin{array}{l}\text { Congenital anomalies of the coronary } \\
\text { arteries }\end{array}$ & $4 / 47$ & $45.8 \pm 9.5$ & $47.7 \pm 12.8$ & 0.70 & $1753 \pm 933$ & $1859 \pm 2868$ & 0.65 \\
\hline
\end{tabular}

Values are mean \pm SD.

${ }^{*}$ Comparisons between $\mathrm{CHD}$ and the controls after adjustment for age and gender.

tIn each CHD group, comparisons between CHD and the age-matched and gender-matched controls (random cluster).

ACC-CHD, anatomic and clinical classification of CHD; CHD, congenital heart disease; OUES ${ }_{\mathrm{kq}^{\prime}}$ weight-normalised oxygen uptake efficiency slope. 


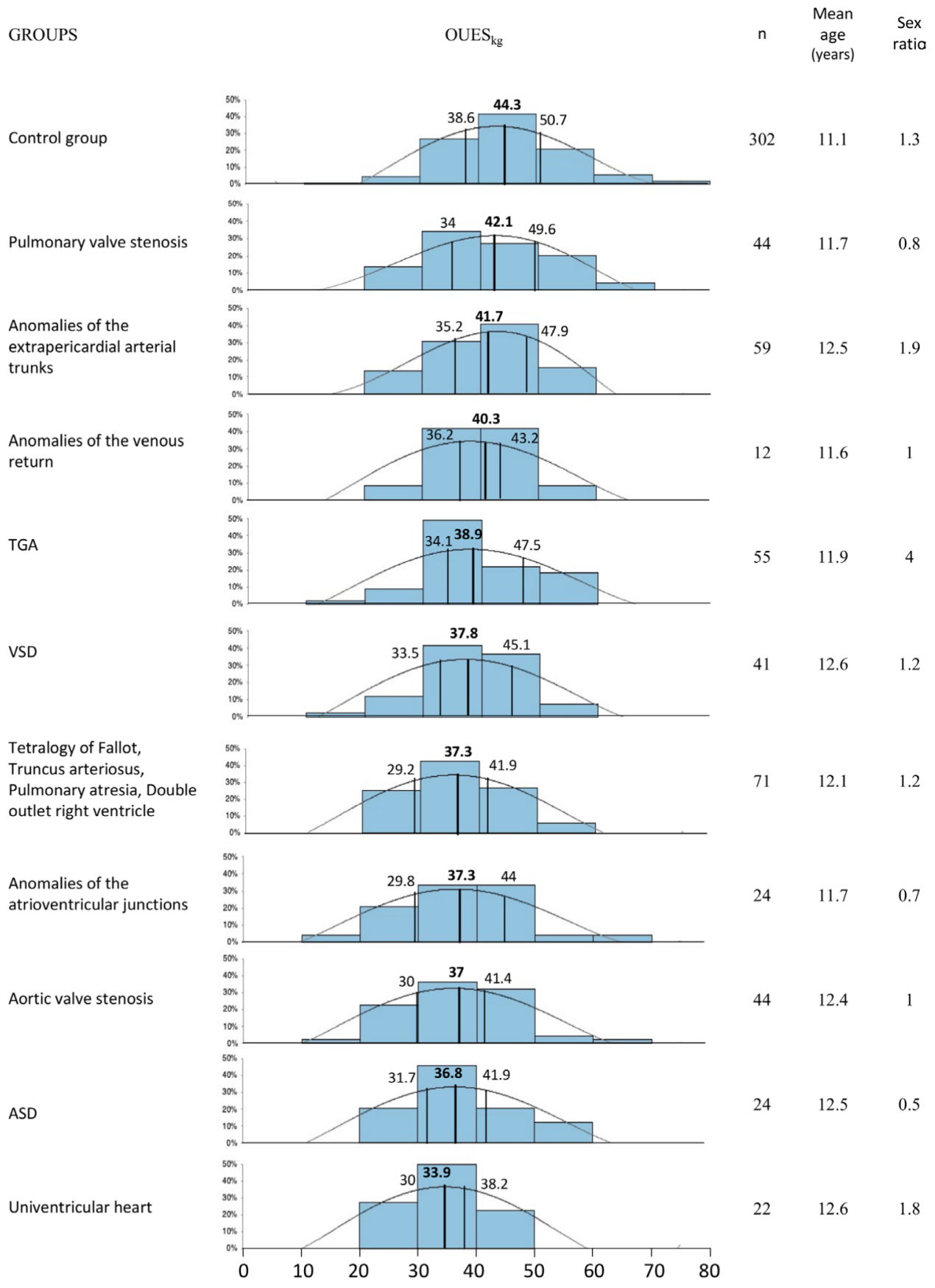

Figure 3 Weight-normalised oxygen uptake efficiency slope (OUES ${ }_{\mathrm{kg}}$ ) in healthy children and children with CHD (histograms). The numbers above the density lines indicate OUES $\mathrm{kg}_{\mathrm{g}}$ values for the 25th, 50th (bold) and 75th percentiles. Histograms represent the distribution of OUES ${ }_{\mathrm{kg}}$ values for controls and each ACC-CHD group. Groups 1, 5 and 10 (small cohorts) were not represented. ACC-CHD, anatomical and clinical classification of congenital heart disease; ASD, atrial septal defect; TGA, transposition of the great arteries; VSD, ventricular septal defect.

\section{Statistics}

The study population was described with means and SD for quantitative variables and with frequencies for qualitative variables. Functional tests results (except for Z-scores) were described with means adjusted on gender and age and SD. The continuous variables distributions were tested using the Shapiro-Wilk test. Quantitative variables were compared using the Student's t-test when the distribution was Gaussian and with the MannWhitney U test, otherwise. For qualitative variables, groups were compared using the $\chi^{2}$ test or Fisher's exact test.

Correlations between $\mathrm{VO}_{2 \max }(\mathrm{mL} / \mathrm{min} / \mathrm{kg})$ and $O \mathrm{OUES}_{\mathrm{kg}}$ were assessed using Pearson's or Spearman's coefficients, depending on the distribution of variables.
To compare all CHD cases and controls, generalised linear models adjusted on gender and age were used, because the number of controls was not sufficient for matching.

For each type of CHD, age-matched and gender-matched control comparisons were performed. For a given CHD case, all the controls with the same gender and age (exact year of age) were used. The case with his (or her) matched-controls was considered as a cluster. Therefore, mixed models were performed in which the clusters were introduced as a random effect.

A multiple linear regression was used to identify the explanatory factors for OUES kg $_{\mathrm{kg}}$ among children with CHD (all types of $\mathrm{CHD}$ combined). The clinically relevant variables with a $\mathrm{p}$ value $\leq 0.2$ in the univariable analysis were included in the model. The 


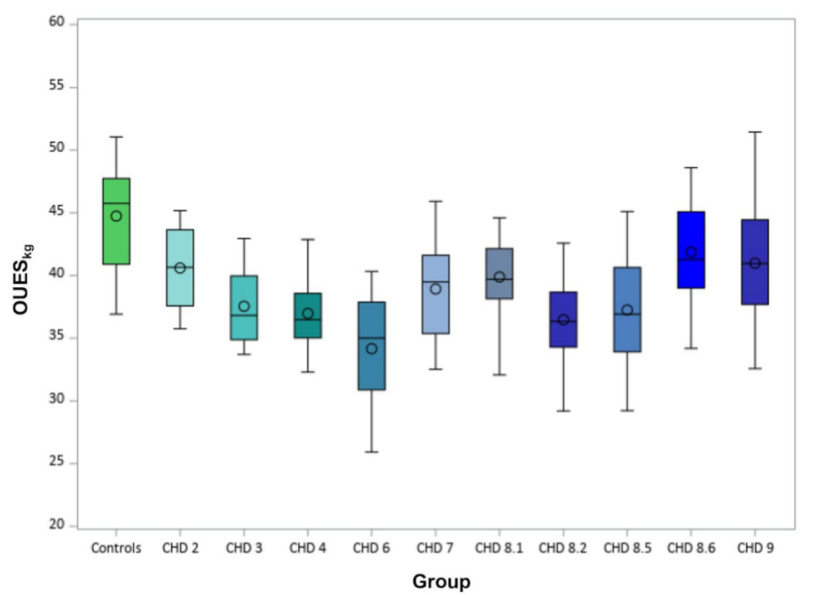

Figure 4 Weight-normalised oxygen uptake efficiency slope (OUES $\mathrm{kg}_{\mathrm{kg}}$ ) in healthy children and children with congenital heart disease (CHD) (box plots). The bottom and top of the box represent the first and third quartiles. Inside the box, the band represents the second quartile (median) and the circle the mean. The whiskers represent the minimum and maximum values.

final model was obtained using an upward selection based on the Akaike information criterion and with an exit threshold of 0.10 . The normality of residues in the final model was tested using the Shapiro-Wilk test.

Receiver operating characteristic (ROC) curve analysis was used to determine the cut-off value of OUES $_{\mathrm{kg}}$ for normal exercise capacity (eg, $\mathrm{VCO}_{2 \max }$ predicts $\geq 80 \%$ ). ROC curves were drawn by plotting the sensitivity against 1 -the specificity. The area under the ROC curve (AUC) was calculated along with its 95\% CI ( $\left.\mathrm{AUC}_{95 \% \mathrm{CI}}\right)$. The cut-off value was determined to optimise both sensitivity and specificity (Youden's Index) and the associated performances were reported (sensitivity, specificity).

The statistical significance was set at 0.05 and analyses were performed using Statistical Analysis Systems V.9 (SAS Institute, Cary, North Carolina, USA).

\section{RESULTS}

\section{Population}

During the 5-year study period, 1915 CPET with OUES were performed in the two laboratories (centre 1: $n=904$, centre 2: $\mathrm{n}=1011)$. Seven hundred nine children were included in the study: 407 children with CHD and 302 controls (figure 1). No families refused to participate. Both groups were similar in terms of demographic data (table 1), except for age as children with CHD were slightly older than healthy controls $(12.2 \pm 3.4$ vs $11.1 \pm 2.6$ years; $p<0.001$, respectively). The demographic data of each CHD groups are summarised in the online supplementary table.

\section{CPET results}

In the $\mathrm{CHD}$ group, the $\mathrm{VCO}_{2 \max }$, the peak heart rate, the maximum load, FEV1 and FVC were significantly lower than in the control group (table 1). The RER and FEV1/FVC were similar in both groups.

In the control group, the mean OUES $_{\mathrm{kg}}$ was $44.7 \pm 9.4$, with

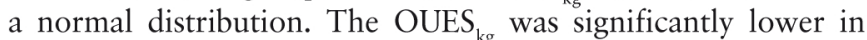
female than male controls $(39.5 \pm 7.3$ vs $48.7 \pm 8.8$, respectively; $\mathrm{p}<0.001$ ) (table 2 and figure 2).

After adjusting on gender and age, the mean OUES $_{\mathrm{kg}}$ of CHD group was significantly lower than in healthy controls. The OUES $_{\mathrm{kg}}$ was predominantly affected in the most severe CHD, such as univentricular heart (group 6) or complex anomalies of ventriculo-arterial connections (group 8.2) (table 2, figures 3 and $4)$. The OUES was significantly lower in the CHD group than in controls, overall $(1583 \pm 464$ vs $1911 \pm 465, \mathrm{p}<0.001$, respectively), as well as in all CHD subgroups except for the three smallest groups (heterotaxy, anomalies of the venous return and anomalies of the coronary arteries).

The cut-off value of OUES $_{\mathrm{kg}}$ for the classification of children with normal functional capacity ( $\geq 80 \%$ of predicted $\mathrm{VO}_{2 \max }$ ) was $38.4\left(\mathrm{AUC}_{95 \% \mathrm{CI}}=0.95(0.91\right.$ to 0.98$\left.)\right)$ for boys and 31.0 $\left(\mathrm{AUC}_{95 \% \mathrm{CI}}=0.92(0.85\right.$ to 0.98$\left.)\right)$ for girls (figure 5).

\section{Factors associated with the OUES}

Overall, OUES $\mathrm{kg}$ and $\mathrm{VO}_{2 \max }(\mathrm{mL} / \mathrm{min} / \mathrm{kg})$ were strongly correlated $(r=0.85, p<0.001)$. Similar results were found in the control group $(r=0.84, p<0.0001)$ and in the CHD group $(\mathrm{r}=0.83, \mathrm{p}<0.0001)$.

Variables associated with a OUES $_{\mathrm{kg}}$ decrease in both univariable and multivariable analyses were an increased age, an increased Body Mass Index (BMI), the number of cardiac catheter or cardiac surgical procedures, the female gender and a decreased
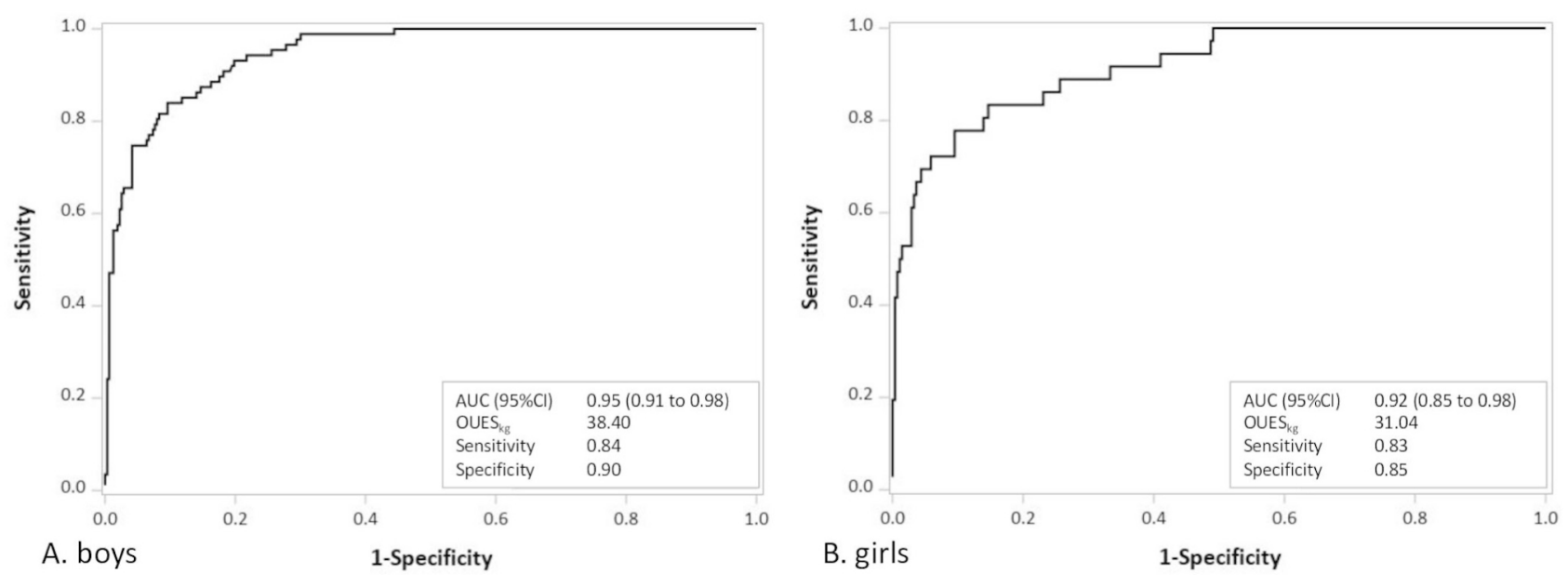

Figure 5 Weight-normalised oxygen uptake efficiency slope $\left(\mathrm{OUES}_{\mathrm{kg}}\right)$ value for normal exercise capacity $\left(\mathrm{VO}_{2 \max }\right.$ predicts $\left.\geq 80 \%\right)$ in boys $(\mathrm{A})$ and girls (B) (congenital heart disease and controls). AUC $(95 \% \mathrm{Cl})$, area under the receiver operating characteristic curve with its $95 \% \mathrm{Cl}$. 
Table 3 OUES $_{\mathrm{kg}}$ explanatory variables in the CHD group

\begin{tabular}{|c|c|c|c|}
\hline & Description & $\begin{array}{l}\text { Univariate } \\
\text { analysis }\end{array}$ & $\begin{array}{l}\text { Multivariate } \\
\text { analysis } \\
(\mathrm{N}=395)\end{array}$ \\
\hline Variables & $r$ & $P$ value & P value \\
\hline Age (years)* & -0.32 & $<0.0001$ & 0.085 \\
\hline $\mathrm{BMI}\left(\mathrm{kg} / \mathrm{m}^{2}\right)^{*}$ & -0.44 & $<0.0001$ & $<0.0001$ \\
\hline FVC (Z-score) $)^{*}$ & 0.11 & 0.031 & $<0.001$ \\
\hline \multirow[t]{2}{*}{ FEV1/FVC (Z-score)* } & 0.08 & 0.088 & - \\
\hline & $\begin{array}{l}\text { OUES }_{\text {kg }} \\
\text { Mean } \pm \text { SD }\end{array}$ & $P$ value & $P$ value \\
\hline \multicolumn{4}{|l|}{ Gender* } \\
\hline Girls & $35.6 \pm 8.5$ & $<0.0001$ & $<0.0001$ \\
\hline Boys & $40.9 \pm 8.8$ & & \\
\hline \multicolumn{4}{|l|}{ ACC-CHD group* } \\
\hline $1,5,10$ & $40.4 \pm 8.5$ & 0.01 & - \\
\hline 2 & $40.6 \pm 6.3$ & & \\
\hline 3 & $36.1 \pm 6.5$ & & \\
\hline 4 & $37.0 \pm 10.8$ & & \\
\hline 6 & $34.2 \pm 7.8$ & & \\
\hline 7 & $39.1 \pm 8.9$ & & \\
\hline 8.1 & $39.7 \pm 9.5$ & & \\
\hline 8.2 & $37.0 \pm 8.2$ & & \\
\hline 8.5 & $37.3 \pm 9.4$ & & \\
\hline 8.6 & $41.0 \pm 10.0$ & & \\
\hline 9 & $40.8 \pm 9.1$ & & \\
\hline \multicolumn{4}{|c|}{ Altered systolic ejection fraction } \\
\hline No & $38.7 \pm 9.2$ & 0.289 & \\
\hline Yes & $36.0 \pm 6.3$ & & \\
\hline \multicolumn{4}{|c|}{ Right ventricle systolic hypertension } \\
\hline No & $38.8 \pm 9.2$ & 0.238 & \\
\hline Yes & $37.5 \pm 8.2$ & & \\
\hline \multicolumn{4}{|c|}{ Left ventricular outflow tract obstacle } \\
\hline No & $38.6 \pm 9.0$ & 0.8 & \\
\hline Yes & $38.4 \pm 9.7$ & & \\
\hline \multicolumn{4}{|c|}{ Right ventricular outflow tract obstacle* } \\
\hline No & $38.2 \pm 9.0$ & 0.053 & - \\
\hline Yes & $41.2 \pm 8.8$ & & \\
\hline \multicolumn{4}{|c|}{ Left ventricular outflow tract regurgitation* } \\
\hline No & $38.8 \pm 9.3$ & 0.112 & - \\
\hline Yes & $36.9 \pm 7.6$ & & \\
\hline \multicolumn{4}{|c|}{ Right ventricular outflow tract regurgitation* } \\
\hline No & $38.9 \pm 9.0$ & 0.154 & - \\
\hline Yes & $37.7 \pm 9.1$ & & \\
\hline \multicolumn{4}{|c|}{ Number of cardiac surgical procedures* } \\
\hline 0 & $39.6 \pm 9.7$ & 0.001 & $<0.001$ \\
\hline 1 & $39.2 \pm 8.5$ & & \\
\hline$\geq 2$ & $35.1 \pm 8.8$ & & \\
\hline \multicolumn{4}{|c|}{ Number of cardiac catheter procedures* } \\
\hline 0 & $38.9 \pm 9.2$ & 0.055 & 0.003 \\
\hline 1 & $38.5 \pm 8.5$ & & \\
\hline$\geq 2$ & $34.3 \pm 8.3$ & & \\
\hline \multicolumn{4}{|l|}{ Medical treatment* } \\
\hline No & $39.0 \pm 9.0$ & 0.01 & - \\
\hline Yes & $35.3 \pm 8.9$ & & \\
\hline \multicolumn{4}{|l|}{ Genetic anomalies* } \\
\hline No & $38.9 \pm 9.0$ & 0.003 & - \\
\hline Yes & $32.1 \pm 7.9$ & & \\
\hline
\end{tabular}

${ }^{*}$ Candidate variables for multivariate analysis.

ACC-CHD, anatomic and clinical classification of CHD; BMI, Body Mass Index; CHD, congenital heart disease; FEV1/FVC, Tiffeneau Index; FVC, forced vital capacity; OUES $_{\mathrm{kg}}$ weight-normalised oxygen uptake efficiency slope.
FVC (Z-score). The final multivariable model explained 38\% of the OUES $_{\mathrm{kg}}$ variability in the CHD group (table 3).

\section{DISCUSSION}

This multicentre controlled study of a large cohort of 709 children presented the OUES values of 407 children with CHD, compared with 302 healthy controls. This study analysed for the first time in this population, the clinical determinants of the OUES $_{\mathrm{kg}}$. Overall, the OUES was significantly lower in children with CHD than in healthy subjects, especially when using the OUES $_{\mathrm{kg}}$. The clinical determinants of a low OUES $\mathrm{kg}$ were the age, the BMI, the female gender, a low FVC, the number of cardiac catheter procedures and the number of cardiac surgical procedures.

The OUES was originally described by Baba et al from a group of paediatric patients. ${ }^{24}$ This is an easily determined parameter stable throughout exercise increment. This index integrates the functional capacities of several organ systems, primarily cardiovascular, pulmonary and skeletal muscle, during exercise. It represents the ventilatory response necessary to increase oxygen supply per unit of muscular oxygen consumption, which is an indicator of how oxygen transport adapts to an increase of muscular oxygen consumption.

Indeed, in exercise testing for patients with heart failure, a decreased OUES may correspond to a defect in pulmonary perfusion with an increased ventilatory perfusion ratio, and/or a defect in systemic perfusion with a decreased oxygen supply to the muscle. ${ }^{27}$ In both cases, a low value of OUES corresponds to an excessive increase of ventilation, which indicates an inefficiency of oxygen transport by cardiopulmonary function.

Our study supports this hypothesis by highlighting the correlation between OUES and CHD severity, as represented by complex CHD and those with numerous cardiac surgical or catheter procedures. Indeed, the OUES was predominantly impaired in the most severe CHD, such as univentricular hearts and complex anomalies of ventriculo-arterial connections.

The OUES was also associated with the pulmonary function, as measured by the spirometry. Indeed, a low FVC suggests the existence of a restrictive pattern, which has been associated with impaired exercise capacity in patients with $\mathrm{CHD} .{ }^{28}$ We also observed the impact of BMI on the OUES, as adipose tissue does not consume oxygen resulting in a low weight-normalised OUES value. Similarly, the lower OUES in girls than in boys may reflect gender differences in muscle mass and adipose tissue. ${ }^{29}$

Overall, the variables associated with OUES in this study were similar to the main determinants of $\mathrm{VO}_{2 \max }{ }^{2}$ Therefore, the OUES may play an important role for exercise capacity assessment in non-maximal exercise, as in patients with severe cardiac conditions. ${ }^{12} 242530$ The existence of a strong correlation between OUES and $\mathrm{VO}_{2 \max }$, for both CHD and healthy controls, is consistent with previous results from smaller or non-controlled cohorts in paediatric ${ }^{2431}$ and adult $^{7}$ populations.

However, the OUES is currently not used in routine follow-up, as opposed to other submaximal CPET parameters, such as VAT and VE/VCO2 slope. ${ }^{32}$ Several explanations may be highlighted. First, the choice of VE to be plotted versus VO2 to calculate OUES can be easily criticised, considering that this parameter is only one of the diffusing limiting steps for oxygen transport. However, like $\mathrm{VO}_{2 \max }$, the OUES should be used as a global parameter of cardiopulmonary and muscular functions, considering that excessive ventilation can be the result of an increased pulmonary ventilation/perfusion ratio, a decreased oxygen supply to the muscle or the presence of muscular deconditioning. 
Second, automatic calculation of OUES has still not been integrated into all CPET technical devices, therefore the use of a logarithmic regression has remained so far in the field of research. Third, although the OUES has been described for more than two decades, standard paediatric values have only been recently reported ${ }^{33}$ which probably contributed to the lack of dissemination in clinical cardiology.

In our study, using the OUES ${ }_{\mathrm{kg}}$ appeared as quite convenient in paediatrics. Similarly, Hossri et al reported that a OUES ${ }_{\mathrm{kg}}$ cutoff value of 34.6 could discriminate children and adolescents with normal exercise capacity (eg, $\geq 80 \%$ of predicted $\mathrm{VCO}_{2 \max }$ ), however both male and female subjects were pooled together in this study. ${ }^{13}$ As suggested by Sun et $a l,{ }^{31}$ gender must be taken into account when considering the OUES. In our study, we identified, with high sensitivity and specificity, OUES ${ }_{\mathrm{kg}}$ cut-off values of 38.4 in boys and 31.0 in girls for the classification of children with normal exercise capacity. In non-maximal cardiopulmonary exercise tests, as frequently observed in children with severe physical conditions, muscular deconditioning, or lack of motivation, the existence of such OUES $_{\mathrm{kg}}$ cut-off values is of great interest, as $\mathrm{VO}_{2 \max }$ may be missing or inaccurate.

A growing body of evidence has shown the prognostic value of OUES, such as in adult patients with pulmonary hypertension, ${ }^{18} 1934$ coronary artery disease ${ }^{35}$ and end-stage heart failure. ${ }^{36}$ Despite more limited prognosis data in paediatrics, the recent study from Tsai $e t$ al reported that OUES could predict cardiac-related hospitalisation in children with tetralogy of Fallot. ${ }^{17}$ Therefore, longitudinal cohort studies remain necessary to determine the prognostic value of OUES, especially in patients with submaximal CPET, as in the CHD population. The OUES will be analysed as a secondary outcome in our currently ongoing randomised QUALI-REHAB trial on centre and homebased cardiac rehabilitation in teenagers and young adults with CHD. $^{37}$

\section{Study limitation}

This study was performed in tertiary care centres and may not represent CHD in the general population. The control group was recruited at the hospital and may not be considered as healthy as if they were recruited from the general population. We thus called them the control children. As in previous studies, spirometry data highlighted the existence of a respiratory restrictive pattern in the CHD population ${ }^{28}$ with a significant impact on OUES. However, further research should measure the total lung capacity with a body plethysmography to evaluate the level of restrictive lung disease.

\section{CONCLUSION}

The OUES is significantly impaired in children with CHD, especially for complex CHD. The OUES is strongly correlated with $\mathrm{VO}_{2 \max }$ and it has the same clinical determinants: age, BMI, female gender, the decrease of FVC (Z-score), the number of cardiac catheter procedures and the number of cardiac surgical procedures. The OUES is known to be reproducible, reliable and interpretable in non-maximal exercise. These data highlight its promising role in non-maximal cardiopulmonary exercise tests where the $\mathrm{VO}_{2 \max }$ would not be interpretable. Using cut-off values of weight-normalised OUES of 38.4 in boys and 31.0 in girls may help identify children with normal functional capacity in non-maximal exercise tests.

Acknowledgements The authors would like to thank Anne Requirand, Annie Auer and Amandine Marquina (CPET laboratory technicians).
Contributors Study concept and design: AG, PA, SM. Drafting of the manuscript: AG, PA, DV. Critical revision of the manuscript for important intellectual content: all statistical analysis: HB, M-CP. Obtained funding: PA.

Funding Montpellier University Hospital Clinical Research Program (PHRC 8422) funded this study.

\section{Competing interests None declared.}

\section{Patient consent for publication Not required.}

Ethics approval This study was conducted in compliance with the Good Clinical Practices and Declaration of Helsinki principles. The French South Mediterranean IV Ethics Committee (2009-A00423-54) gave its approval and all parents or legal guardians gave their informed consent.

Provenance and peer review Not commissioned; externally peer reviewed.

Data availability statement All data relevant to the study are included in the article or uploaded as supplementary information.

\section{REFERENCES}

1 Guazzi M, Adams V, Conraads V, et al. Clinical recommendations for cardiopulmonary exercise testing data assessment in specific patient populations. Circulation 2012;126:2261-74.

2 Amedro P, Gavotto A, Guillaumont S, et al. Cardiopulmonary fitness in children with congenital heart diseases versus healthy children. Heart Br Card SoC 2018;104:1026-36.

3 Amedro P, Picot MC, Moniotte S, et al. Correlation between cardio-pulmonary exercise test variables and health-related quality of life among children with congenital heart diseases. Int J Cardiol 2016;203:1052-60.

4 Barker AR, Williams CA, Jones AM, et al. Establishing maximal oxygen uptake in young people during a ramp cycle test to exhaustion. Br J Sports Med 2011:45:498-503

5 Rowland TW, Cunningham LN. Oxygen uptake plateau during maximal treadmill exercise in children. Chest 1992:101:485-9.

6 Andreacci JL, LeMura LM, Cohen SL, et al. The effects of frequency of encouragement on performance during maximal exercise testing. J Sports Sci 2002;20:345-52.

7 Hollenberg M, Tager IB. Oxygen uptake efficiency slope: an index of exercise performance and cardiopulmonary reserve requiring only submaximal exercise. J Am Coll Cardiol 2000;36:194-201.

8 Müller J, Böhm B, Semsch S, et al. Currently, children with congenital heart disease are not limited in their submaximal exercise performance. Eur J Cardiothorac Surg 2013:43:1096-100.

9 Paolillo S, Veglia F, Salvioni E, et al. Heart failure prognosis over time: how the prognostic role of oxygen consumption and ventilatory efficiency during exercise has changed in the last 20 years. Eur J Heart Fail 2019;21:208-17.

10 Baba R, Nagashima M, Nagano Y, et al. Role of the oxygen uptake efficiency slope in evaluating exercise tolerance. Arch Dis Child 1999;81:73-5.

11 Van Laethem C, Bartunek J, Goethals M, et al. Oxygen uptake efficiency slope, a new submaximal parameter in evaluating exercise capacity in chronic heart failure patients. Am Heart J 2005; 149:175-80.

12 Bongers BC, Hulzebos EH, Helbing WA, et al. Response profiles of oxygen uptake efficiency during exercise in healthy children. Eur J Prev Cardiol 2016;23:865-73.

13 Hossri CA, Souza IPAde, de Oliveira JS, et al. Assessment of oxygen-uptake efficiency slope in healthy children and children with heart disease: generation of appropriate reference values for the OUES variable. Eur J Prev Cardiol 2019;26:177-84

14 Bongers BC, Hulzebos HJ, Blank AC, et al. The oxygen uptake efficiency slope in children with congenital heart disease: construct and group validity. Eur J Cardiovasc Prev Rehabil 2011;18:384-92.

15 Chen $\mathrm{C}-\mathrm{A}$, Chen S-Y, Chiu H-H, et al. Prognostic value of submaximal exercise data for cardiac morbidity in Fontan patients. Med Sci Sports Exerc 2014;46:10-15.

16 Sun X-G, Hansen JE, Stringer WW. Oxygen uptake efficiency plateau best predicts early death in heart failure. Chest 2012;141:1284-94.

17 Tsai Y-J, Li M-H, Tsai W-J, et al. Oxygen uptake efficiency slope and peak oxygen consumption predict prognosis in children with tetralogy of Fallot. Eur J Prev Cardiol 2016:23:1045-50.

18 Ramos RP, Ota-Arakaki JS, Alencar MC, et al. Exercise oxygen uptake efficiency slope independently predicts poor outcome in pulmonary arterial hypertension. Eur Respir $J$ 2014:43:1510-2.

19 Tang Y, Luo Q, Liu Z, et al. Oxygen uptake efficiency slope predicts poor outcome in patients with idiopathic pulmonary arterial hypertension. J Am Heart Assoc 2017;6. doi:10.1161/JAHA.116.005037. [Epub ahead of print: 30 Jun 2017].

20 Houyel L, Khoshnood B, Anderson RH, et al. Population-Based evaluation of a suggested anatomic and clinical classification of congenital heart defects based on the International paediatric and congenital cardiac code. Orphanet I Rare Dis 2011;6:64. 
21 Zapletal A, Motoyama EK, Van De Woestijne KP, et al. Maximum expiratory flowvolume curves and airway conductance in children and adolescents. J Appl Physiol 1969;26:308-16

22 Takken T, Blank AC, Hulzebos EH, et al. Cardiopulmonary exercise testing in congenital heart disease: equipment and test protocols. Neth Heart J 2009;17:339-44.

23 Cooper DM, Berry C, Lamarra N, et al. Kinetics of oxygen uptake and heart rate at onset of exercise in children. J Appl Physiol 1985;59:211-7.

24 Baba R, Nagashima M, Goto M, et al. Oxygen uptake efficiency slope: a new index of cardiorespiratory functional reserve derived from the relation between oxygen uptake and minute ventilation during incremental exercise. J Am Coll Cardiol 1996:28:1567-72.

25 Akkerman $\mathrm{M}$, van Brussel M, Bongers BC, et al. Oxygen uptake efficiency slope in healthy children. Pediatr Exerc Sci 2010;22:431-41.

26 Drinkard B, Roberts MD, Ranzenhofer LM, et al. Oxygen-uptake efficiency slope as a determinant of fitness in overweight adolescents. Med Sci Sports Exerc 2007;39:1811-6.

27 Myers J, Arena R, Dewey F, et al. A cardiopulmonary exercise testing score for predicting outcomes in patients with heart failure. Am Heart J 2008;156:1177-83.

28 Abassi H, Gavotto A, Picot MC, et al. Impaired pulmonary function and its association with clinical outcomes, exercise capacity and quality of life in children with congenital heart disease. Int I Cardio/ 2019;285:86-92.

29 Matecki S, Prioux J, Amsallem F, et al. [Maximal oxygen uptake in healthy children: factors of variation and available standards]. Rev Mal Respir 2001;18:499-506.
30 Marinov B, Kostianev $S$. Exercise performance and oxygen uptake efficiency slope in obese children performing standardized exercise. Acta Physiol Pharmacol Bulg 2003:27:59-64.

31 Sun X-G, Hansen JE, Stringer WW. Oxygen uptake efficiency plateau: physiology and reference values. Eur J Appl Physiol 2012;112:919-28.

32 Mezzani A, Agostoni P, Cohen-Solal A, et al. Standards for the use of cardiopulmonary exercise testing for the functional evaluation of cardiac patients: a report from the exercise physiology section of the European association for cardiovascular prevention and rehabilitation. Eur J Cardiovasc Prev Rehabil 2009;16:249-67.

33 Takken T, Mylius CF, Paap D, et al. Reference values for cardiopulmonary exercise testing in healthy subjects - an updated systematic review. Expert Rev Cardiovasc Ther 2019;17:413-26.

34 Shi X, Liu J, Guo J, et al. [Correlation between submaximal exercise measurements and peak oxygen uptake in patients with pulmonary arterial hypertension]. Zhonghua Yi Xue Za Zhi 2014;94:2490-4

35 Coeckelberghs E, Buys R, Goetschalckx K, et al. Prognostic value of the oxygen uptake efficiency slope and other exercise variables in patients with coronary artery disease. Eur J Prev Cardiol 2016;23:237-44.

36 Lin Y-S, Huang H-Y, Lin W-H, et al. Oxygen uptake efficiency slope predicts major cardiac events in patients with end-stage heart failure. Transplant Proc 2016:48:956-8.

37 Amedro P, Gavotto A, Legendre A, et al. Impact of a centre and home-based cardiac rehabilitation program on the quality of life of teenagers and young adults with congenital heart disease: the QUALI-REHAB study rationale, design and methods. Int 1 Cardiol 2019;283:112-8. 